Pesq. Vet. Bras. 36(3):227-236, março 2016 DOI: $10.1590 / \mathrm{S} 0100-736 \mathrm{X} 2016000300013$

\title{
Morfologia das glândulas salivares maiores em cutias (Dasyprocta leporina Linnaeus, 1766) ${ }^{1}$
}

\author{
Carlos M. Oliveira Júnior², Ferdinando V.F. Bezerra² ${ }^{2}$ Felipe V. Câmara² ${ }^{2}$ André M. do Vale², \\ Gleidson B. de Oliveira², Alexandre R. da Silva² , Carlos E. Ambrosio ${ }^{3}$ e Moacir F. Oliveira ${ }^{2 *}$
}

\begin{abstract}
Oliveira Júnior C.M., Bezerra F.V.F., Câmara F.V., Vale A.M., Oliveira G.B., Silva A.R., Ambrosio C.E. \& Oliveira M.F. 2016. [Morphology of the larger salivar glands of red-rumped agouti (Dasyprocta leporina Linnaeus, 1766.] Morfologia das glândulas salivares maiores em cutias (Dasyprocta leporina Linnaeus, 1766). Pesquisa Veterinária Brasileira 36(3):227-236. Departamento de Ciências Animais, Universidade Federal Rural do Semi-Árido, Avenida Francisco Mota 572, Costa e Silva, Mossoró, RN 59625-900, Brazil. E-mail: moacir@ufersa.edu.br

Studies on wild animal morphology serve as theoretical basis for the management and conservation of different species, because they provide necessary information for measures to keep these animals in captivity, in their natural habitat or even to reintroduce them into their original habitat. Studies about the morphology of the red-rumped agouti, Dasyprocta leporina, approach the various organic systems, but not a single study refers to topography and structure arrangement of their salivary glands. Thus, this paper aimed to gross and microscopic description of the larger salivary glands of red-rumped agouti. Ten adult $D$. leporina were used to study the macroscopic aspect of the glands, as well as the microscopic aspects with light microscopy, scanning and transmission electronic microscopy. Four larger salivary glands were identified: parotid glands, mandibular glands, zygomatic glands and sublingual glands. The tubuloacinar glands contained in their parenchyma ducts of extremely varied sizes. With exception of the strictly serous parotid glands, the others were mixed, and only the mandibular glands had granulous ducts. The red-rumped agouti with four pairs of larger salivary glands may be a model for studies concerning the anatomical changes in rodents for adaptation to various habitats.
\end{abstract}

INDEX TERMS: Salivary glands, rodent, red-rumped agouti, Dasyprocta aguti, macro and microscopy.

RESUMO.- Estudos acerca da morfologia de animais silvestres servem de subsídio para trabalhos de manejo e preservação de diferentes espécies, pois fornecem informações para a tomada de medidas que auxiliem na manutenção destes em cativeiro, na preservação em habitat natural ou mesmo para ações voltadas a reintrodução ao habitat de origem. Estudos referentes à morfologia de cutias abordam os diversos sistemas, mas nenhum faz referência à arquitetura ou estrutura de suas glândulas salivares. As-

\footnotetext{
${ }^{1}$ Recebido em 12 de março de 2015.

Aceito para publicação em 21 de dezembro de 2015.

2 Departamento de Ciências Animais, Universidade Federal Rural do Semi-Árido (UFERSA), Av. Francisco Mota 572, Costa e Silva, Mossoró, RN 59625-900, Brasil. *Autor para correspondência: moacir@ufersa.edu.br

${ }^{3}$ Faculdade de Zootecnia e Engenharia de Alimentos (FZEA), Departamento de Medicina Veterinária, Universidade de São Paulo (USP), Av. Duque de Caxias Norte, 225, Pirassununga, SP 13635-900, Brasil.
}

sim este trabalho objetivou descrever macro e microscopicamente as glândulas salivares maiores de cutias. Foram utilizados dez animais adultos para o desenvolvimento de metodologias relativas à macroscopia propriamente dita das glândulas, microscopia de luz, microscopia eletrônica de transmissão e microscopia eletrônica de varredura. Foram identificadas quatro glândulas salivares maiores nos animais estudados, denominadas parótida, mandibular, zigomática e sublingual. As glândulas apresentaram-se como sendo do tipo tubuloacinares e contendo em seu parênquima ductos dos mais variados tamanhos. Com exceção da glândula parótida, que era estritamente serosa, as demais eram mistas. Da mesma forma, apenas a glândula mandibular foi identificada a presença de ducto do tipo granuloso. Apresentando as cutias os quatro pares de glândulas salivares maiores, estes animais podem servir de modelo para os estudos acerca das mudanças anatômi- 
cas sofridas pelos roedores para se adaptar aos diversos habitat do planeta.

TERMOS DE INDEXAÇÃO: Glândulas salivares, roedor, cutia, Dasyprocta aguti, macroscopia e microscopia.

\section{INTRODUÇÃO}

A pesquisa com animais silvestres fornece embasamento para preservação de espécies ameaçadas de extinção e também para sua manutenção em cativeiro, em se tratando de biodiversidade, o Brasil ocupa posição ímpar e as possibilidades para pesquisas científicas são inúmeras, ademais, entender como estes animais se alimentam, vivem e como está disposta sua anatomia, fornece subsídios a pesquisadores e também a populações humanas dependentes de animais silvestres para alimentação. Neste campo, poucos seres são tão dinâmicos e ocupam tantas posições geográficas do globo terrestre quanto os roedores, esses animais sofreram várias adaptações anatômicas para que pudessem sobreviver em ambientes distintos, seu surgimento data do eoceno e convivem com o ser humano, tanto trazendo benefícios quanto malefícios (Carleton \& Musser 2005), dentre a enorme diversidade de roedores, encontra-se a cutia.

As cutias são caracterizadas por apresentar o corpo grosso, a cabeça um pouco alongada com orelhas relativamente pequenas (Marcelo 2005). Para Deutsch Puglia (1988) o comprimento médio de uma cutia é de $50 \mathrm{~cm}$, medindo-se da base da cauda ao focinho, sua altura média está em torno de $23 \mathrm{~cm}$ e o seu peso não ultrapassa os 3 kg. Nowak (1991), Emmons \& Feer (1997) descrevem sua cauda como vestigial, seus membros anteriores bem mais curtos que os posteriores. Os membros posteriores são compridos e com cinco dedos, sendo três desenvolvidos, com unhas cortantes e o quinto dedo muito reduzido. Para conseguir sobreviver durante o período de escassez de alimentos, durante a estação seca, esses animais alteram a sua alimentação, passando a ingerir alimentos como sementes e para conseguir isso eles sofrem alterações na constituição salivar, facilitando a ingestão de alimentos pouco aquosos, no entanto, apesar de bem documentadas em várias espécies de animais, as glândulas salivares não foram pesquisadas em cutias o conhecimento utilizado nestes animais advém de pesquisas feitas em outros roedores. Levando em consideração esse fator, o presente artigo visa preencher lacunas para este grupo de animais.

\section{MATERIAL E MÉTODOS}

Para desenvolvimento deste estudo foram utilizadas 10 cutias adultas (independentemente do sexo), obtidas do Centro de Multiplicação de Animais Silvestres da Universidade Federal Rural do Semi-Árido (CEMAS/UFERSA). Os animais foram pré-anestesiados, anestesiados e eutanasiados. A metodologia utilizada no projeto foi aprovada pelo SISBIO (Parecer no 35235-1) e também pela Comissão de Ética no Uso de Animais (CEUA) da UFERSA (Parecer nำ 67/2012).

Microscopia de luz. As amostras coletadas eram fixadas com paraformaldeído a $4 \%$ tamponado com fosfato de sódio $0,1 \mathrm{M}, \mathrm{pH}$ 7,4 a $4^{\circ} \mathrm{C}$, após a fixação eram desidratados em uma série crescente de álcoois, diafanizados, parafinizados e corados com Hemato-
xilina-Eosina (HE), Ácido Periódico de Schiff (PAS), Azul de Toluidina, Alcian Blue $(2,5)$, Ácido Periódico de Schiff (PAS) associado com Alcian Blue $(2,5)$ e o Tricrômico de Gomori.

Microscopia eletrônica de transmissão. As amostras eram imersas em solução de glutaraldeído a 2,5\% tamponado com fosfato de sódio 0,1 molar em pH 7,4 a $4^{\circ} \mathrm{C}$ para fixação, lavadas com solução tampão fosfato de sódio, pós-fixadas em tetróxido de ósmio a $2 \%$, contrastadas com acetato de uranila a $3 \%$. 0 material era desidratado em concentrações crescentes de álcool etílico, lavados com óxido de propileno, óxido de propileno-resina e resina Spurr. Polimerizados e cortados com o auxílio de um ultra-micrótomo, contrastados com acetato de uranila a 2\% e citrato de chumbo a $5 \%$ para posterior visualização em microscópio eletrônico de transmissão.

Microscopia eletrônica de varredura. Fragmentos eram fixados em solução de glutaraldeído a 2,5\% tamponado com fosfato de sódio $0,1 \mathrm{M}$, pH 7,4 a $4^{\circ} \mathrm{C}$, lavados em solução tampão fosfato de sódio $0,1 \mathrm{M}, \mathrm{pH} 7,4$ a $4^{\circ} \mathrm{C}$, pós-fixados com tetróxido de ósmio a $1 \%$ tamponado com fosfato de sódio 0,1M e pH 7,4, por duas horas. Em seguida o material foi tratado com ácido tânico a 1\% e desidratado em série crescente de concentrações de álcoois. 0 material foi seco em aparelho de ponto crítico utilizando gás carbônico $\left(\mathrm{CO}_{2}\right)$, fixado em suporte do ponto de amostra (Stub) e metalizado com paladium por "sputtring", para observação em microscópio eletrônico de varredura.

\section{RESULTADOS}

Foram encontrados quatro grupos de glândulas salivares maiores: a parótida, a mandibular, a zigomática e a sublingual. A parótida era a maior entre as quatro glâdulas (Fig. 1A). Possuía forma irregular, dotada de vários pequenos lobos e localizava-se no ponto de união entre a cabeça e o pescoço, na interssecção do masseter e a cartilagem auricular. Estendia-se dorsalmente a partir da glândula mandibular em direção à base da orelha e seguia na região cervical, além disso, ela cobria a porção cranial da glândula mandibular. Era evidente sua lobação externa e sua cor rosa. De sua porção rostral originava-se seu ducto principal, que em seu trajeto passava dorsalmente sobre o músculo masseter superficial (Fig.1A). A glândula mandibular estava disposta próximo ao ângulo da mandíbula, fazia limite rostralmente com os linfonodos mandibulares e dorsalmente com a parte ventral da glândula parótida. Ventralmente fazia sintopia com o músculo digástrico. Possuía forma triângular e cor amarelo pálido. Era facilmente identificada, após rebatimento da porção ventral da parótida e apresentava macrolobação à luz da macroscopia (Fig.1A,B). A glândula zigomática era observável após rebatimento do músculo zigomático-auricular, logo após o processo temporal do osso zigomático, entre os músculos masseter e temporal, disposta na região suborbital. Possuía forma oblonga e cor variando de vermelho ao marrom (Fig.1A). A glândula sublingual monostomática localizou-se próxima ao ângulo da mandibula, medianamente em relação a glândula mandibular, separada desse pelo músculo estiloglosso. Era uma glândula protegida por uma cápsula fibrosa, lobulada, difusa e de cor amarelo pálido. A glândula sublingual polistomática era a menor das quatro glândulas salivares analisadas e consistia em um par de estruturas localizadas próximas a base da língua, no assoalho oral, abaixo da membrana do pavimento da boca, fronteirando com a 


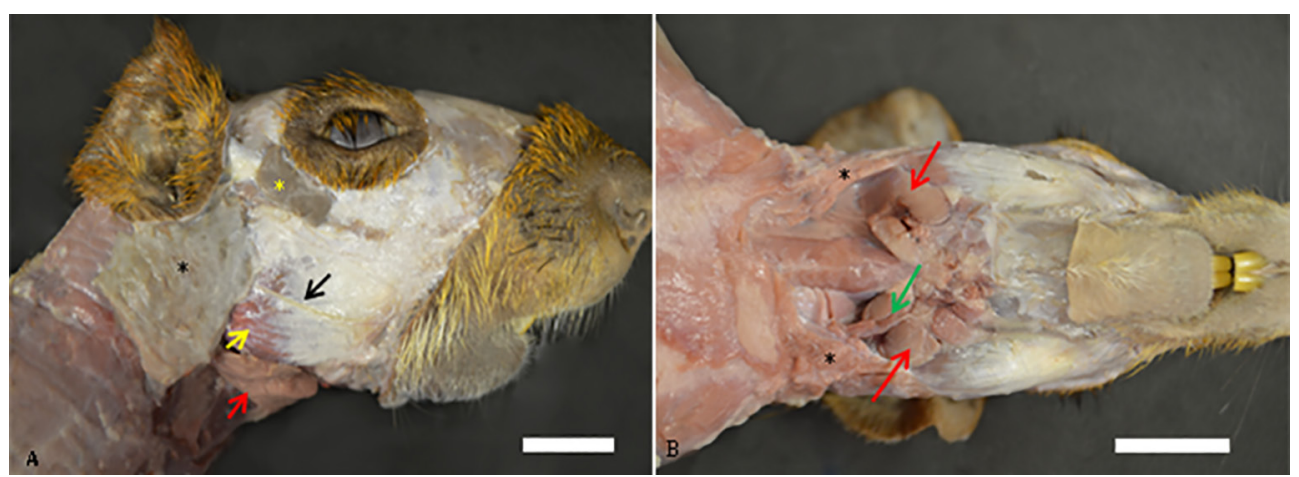

Fig.1. (A) Região cranial de cutias. 0 ducto parotídeo (seta preta) parte da glândula parótida (asterisco preto) e passa sobre a região medial do músculo masseter (seta amarela) até adentrar na cavidade oral. Próximo ao olho observa-se a glândula zigomática (asterisco amarelo) e fazendo sintopia com o músculo masseter, verifica-se a glândula mandibular (seta vermelha). (B) Região cranial de cutias. A glândula parótida (astericos) fica próxima da glândula mandibular (setas vermelhas), sobre a região medial da glândula mandibular passa a veia linguofacial (seta verde). A barra corresponde a $3 \mathrm{~cm}$.

fóvea mandibular e o músculo genioglosso. A mesma não apresentou lobação, sua forma era oblonga e possuía cor vermelha intensa.

Pela micrsocopia de luz, verificou-se que as glândulas eram túbulo-alveolares que se conectavam por meio de ductos. Em relação íntima com os ácinos estavam os ductos intercalares ao redor deles verificou-se uma fina fita de fibra colágena. Eram revestidos por epitélio cúbico, com um citoplasma eosinófilo e volumoso. Estas células apresentaram núcleos grandes, redondos, pouco basofílicos e localizados, geralmente, no centro das células e com os nucléolos evidentes (Fig.2A e 2B). Os ductos granulosos, encontrados apenas nas glândulas mandibulares, eram intermediários entre os ductos intercalares e estriados e possuíam vários grânulos de secreção na região apical das células. Caracterizavam-se por possuírem uma única camada de células variando de cúbicas a colunares baixas, com pouco espaço citoplasmático e de aspecto eosinofílico. Apresentaram núcleo grande, pouco basofílico, heterocromático e dispostos, em geral, próximos à região basal das células. Possuíam ainda, um nucléolo proeminente (Fig.2C e 2D). Os ductos estriados eram ductos intralobulares, com pouco tecido conjuntivo circundante e com limites definidos por uma fina camada de colágeno. Eram revestidos por uma única camada de epitélio cilíndrico alto, com células contendo núcleos alongados, pouco basofílicos e dispostos centralmente ou próximos ao ápice celular, seus nucleólos eram pouco evidentes. Suas camadas mais internas eram cúbicas, com um citoplasma reduzido e eosinofílico e núcleos redondos e pouco basofílicos. Além disso, os nucleólos eram pouco evidentes. A camada mais externa possuía um epitélio colunar alto, cujas células possuíam citoplasma eosinofílico, núcleos pouco basofílicos, alongados e localizados no centro da célula, os nucléolos eram evidentes (Fig.2E e 2F). Os ductos excretores estavam dispostos entre os lóbulos das glândulas. Estes se caracterizavam por apresentarem bastante tecido conjuntivo ao seu redor e ser circundados por uma camada considerável de fibras colágenas. Possuíam de duas a três camadas de tecido epitelial (Fig.2G e 2H).

A glândula parótida estava dividida em lóbulos, separados por tecido conjuntivo denso não-modelado. Os lóbulos eram constituídos por células acinares predominantemente serosas (Fig.3A e 3B). Os ácinos serosos eram circundados por poucas fibras colágenas e algumas células mioepiteliais. Suas células acinares apresentaram forma piramidal, citoplasma com estriações, indicando atividade secretora. Os núcleos dessas células apresentaram-se dispostos na região basal, eram redondos, heterocromáticos e apresentaram o nucléolo evidente (Fig.4A e 4B).

A glândula mandibular tinha seus lobos divididos em lóbulos, separados por tecido conjuntivo denso não-modelado (Fig.3C e 3D). A mesma apresentou tanto células serosas, quanto mucosas e predominância de ácinos mucosos. Os ácinos mucosos eram constituídos por células piramidais altas, a maior parte do citoplasma célular é constituída por grânulos de secreção, que se concentraram em maior quantidade na porção apical das células. Os núcleos localizavam-se na porção basal da célula, eram redondos e com núcleos fortemente corados pela hematoxilina. Já as células serosas, apresentaram-se como semiluas serosas e possuíam uma grande similaridade com as células serosas da parótida, possuindo forma piramidal e vários grânulos de secreção proteicos próximos ao ápice celular (Fig.4C e 4D).

A zigomática apresentou tanto ácinos serosos, quanto mucosos (Fig.3E e 3F). Os ácinos mucosos ocuparam a maior parte da glândula. As células acinosas mucosas possuíam forma piramidal, citoplasma completamente preenchido por grânulos de secreção. Os núcleos eram basofílicos, localizados basalmente, possuíam forma esférica e eram pequenos. As células serosas, por sua vez, apareceram na forma de semiluas serosas e eventualmente, em ácinos puramente serosos. As células serosas também possuíam forma piramidal, citoplasma tomado por grânulos de secreção, principalmente na região apical. 0 núcleo corou-se fortemente pela hematoxilina, estava disposto na região basal das células, eram pequenos e redondos (Fig.4E e 4F). Os ácinos da glândula sublingual eram, em sua maioria, mucosos e com regiões de semiluas serosas (Fig.3G e 3H). Os ácinos mucosos sublinguais possuíam grandes células piramidais produtoras de muco, com citoplasma abundante e cheio de grânulos de secreção. A região basal das células corou-se fortemente pela hematoxilina. Os núcleos 

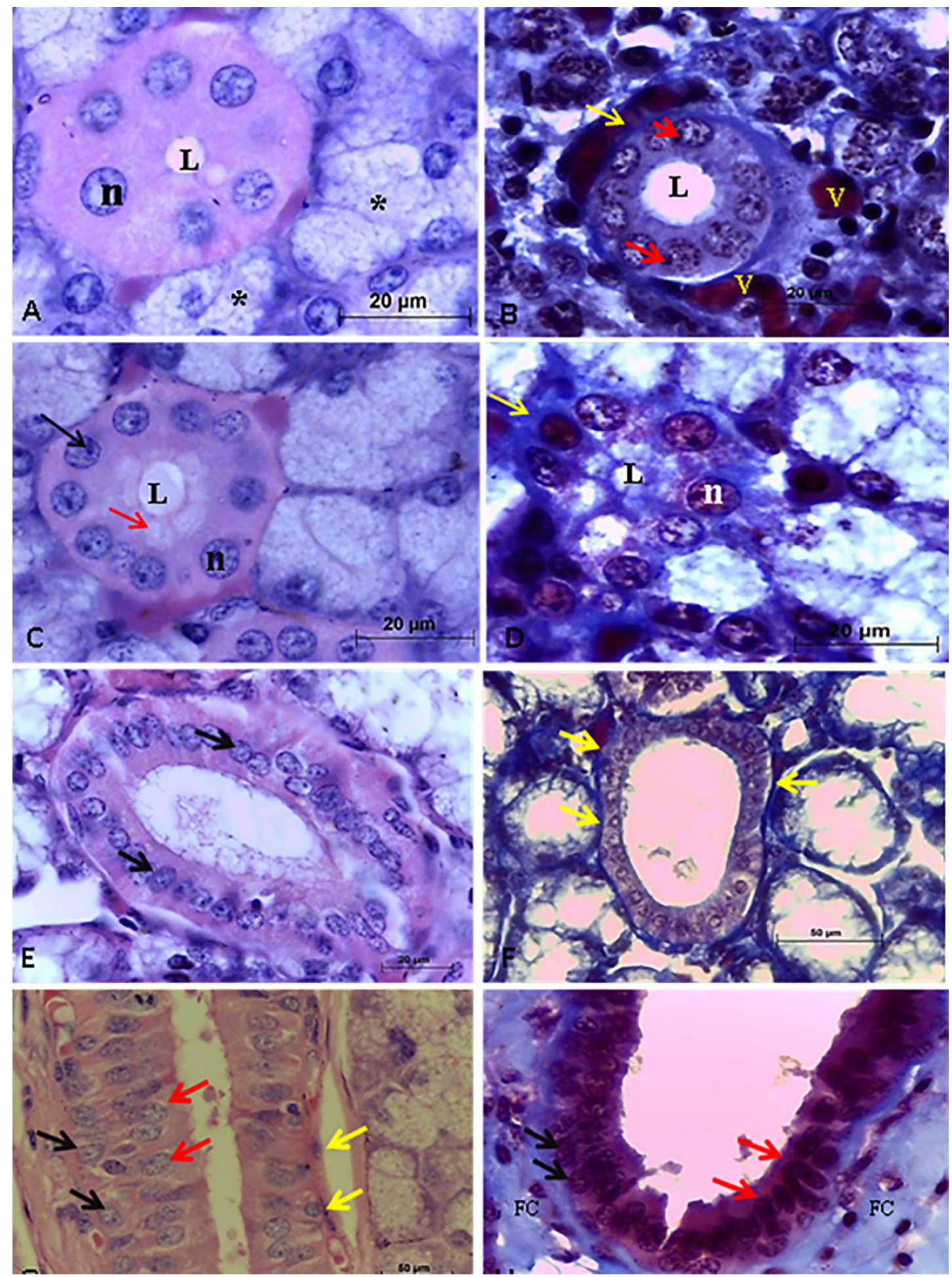

Fig.2. Os ductos das glândulas salivares de cutia. (A) Ducto intercalar rodeado de ácinos mucosos (*). As células ductais são cúbicas, pequenas e eosinofílicas. Os núcleos (n) são grandes, pouco basofílicos e os nucléolos pouco evidentes. (B) 0 mesmo ducto envolto por uma fina fita de colágeno (Seta amarela) que delimita-o externamente. Luz dos ductos (L). Vasos sanguíneos (V). (C) As células do ducto granuloso são cúbicas, pequenas e eosinofílicas. No ápice do citoplasma, percebem-se grânulos de secreção (seta vermelha). Ao centro das células ductais está o lúmen do ducto (L). Os núcleos (N) são grandes, pouco basofílicos, ocupam grande parte do citoplasma e possuem nucléolos evidentes (setas pretas). (D) Uma fita de fibra colágena delimita o ducto granuloso. (E) As células do ducto estriado são colunares. 0 citoplasma é eosinofílico e os núcleos (setas pretas) estão localizados no centro das células. (F) Uma fina fita de colágeno (seta amarela) ao redor do ducto. (G) As células epiteliais basais do ducto excretor são cúbicas e os núcleos esféricos e basofílicos (setas pretas). As células mais superficiais são colunares e seu núcleo (setas vermelhas) localiza-se centralmente. Verifica-se a presença de células mioepiteliais (setas amarelas). (H) Ducto excretor rodeado por fibra colágena (FC), as células mais basais possuem núcleo esférico (setas pretas) e as células mais externas são colunares e com núcleo central (setas vermelhas). (A,C,E,G) Coloração Hematoxilina-Eosina. (B,D,F,H) Coloração Tricrômico de Gomori. (A-E) Obj.100x. (F-H) Obj.40x. 

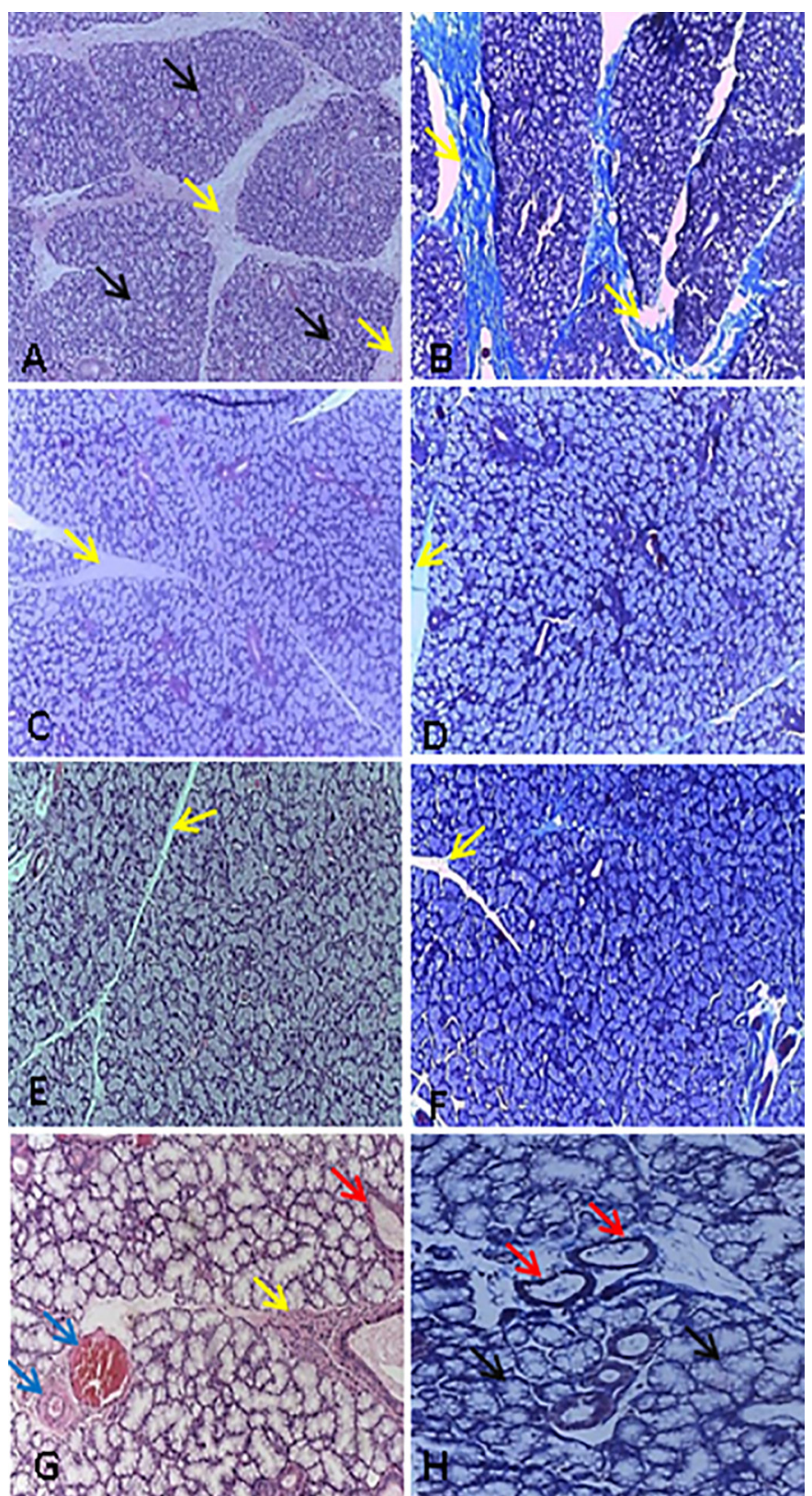

Fig.3. Glândulas salivares de cutia. (A) Os vários lóbulos (setas pretas) da glândula parótida separados uns dos outros por meio de tecido conjuntivo (setas amarelas). (B) Os lóbulos da glândula parótida estão divididos por grande quantidade de fibras colágenas (setas amarelas). (C) Detalhes dos lóbulos mucosos da glândula mandibular, os lóbulos são divididos por pouco tecido conjuntivo (seta amarela). Notar a presença de vários ductos. (D) A mandibular possui poucas fibras colágenas dividindo-a, notam-se vários ductos. (E) Os ácinos da glândula zigomática estão divididos por pouco tecido conjuntivo (seta amarela). (F) Há poucas fibras colágenas ao (seta amarela) redor dos ácinos os ácinos. (G) Os ácinos mucosos da glândula sublingual são grandes e estão divididos por pouco tecido conjuntivo (seta amarela), observam-se também, ductos (seta vermelha), notar também a presença de vasos sanguíneos (setas azuis). (H) Ductos (setas vermelhas) e ácinos (setas pretas) são divididos por poucas fibras colágenas. (A,C,E,G) Coloração Hematoxilina-Eosina. (B,D,F,H) Coloração Tricrômico de Gomori. Obj.40x.
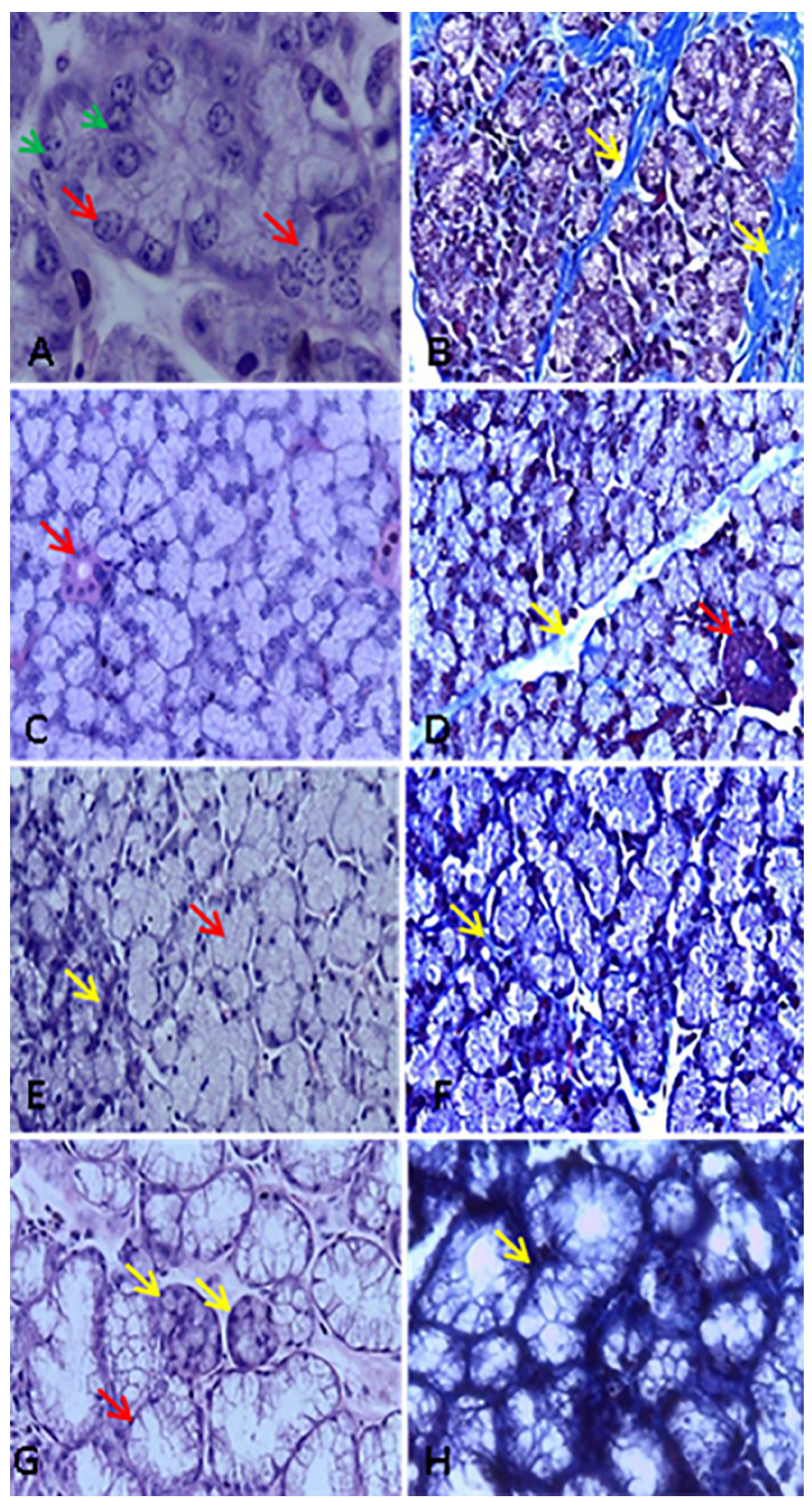

Fig.4. Glândulas salivares de cutia. (A) Ácinos serosos da glândula parótida mostrando os núcleos (setas vermelhas) basofílicos e com nucléolos evidentes (seta verdes). (B) Presença de fibras colágenas (setas amarelas) entremeando os ácinos, de forma a individualiza-los. (C) Detalhes dos ácinos mucosos da glândula mandibular. Notar a presença de um ducto intercalar (seta vermelha). (D) Poucas fibras colágenas (seta amarela) ao redor dos ácinos da glândula mandibular, notar a presença de um ducto estriado (seta vermelha). (E) Ácinos mucosos (seta vermelha) e ácinos serosos (seta amarela) da glândula zigomática. (F) Os ácinos da glândula zigomática estavam cercados por poucas fibras colágenas (seta amarela). (G) Ácinos mucosos (seta vermelha) e ácinos serosos (seta amarela) da glândula sublingual. Notar que os ácinos da glândula mandibular são maiores que os ácinos das demais glândulas. (H) Os ácinos da glândula sublingual estavam cercados por poucas fibras colágenas (setas). (A,C,E,G) Coloração Hematoxilina-Eosina. (B,D,F,H) Coloração Tricrômico de Gomori. (A) Obj.100x. (B-H) Obj. 40x. 


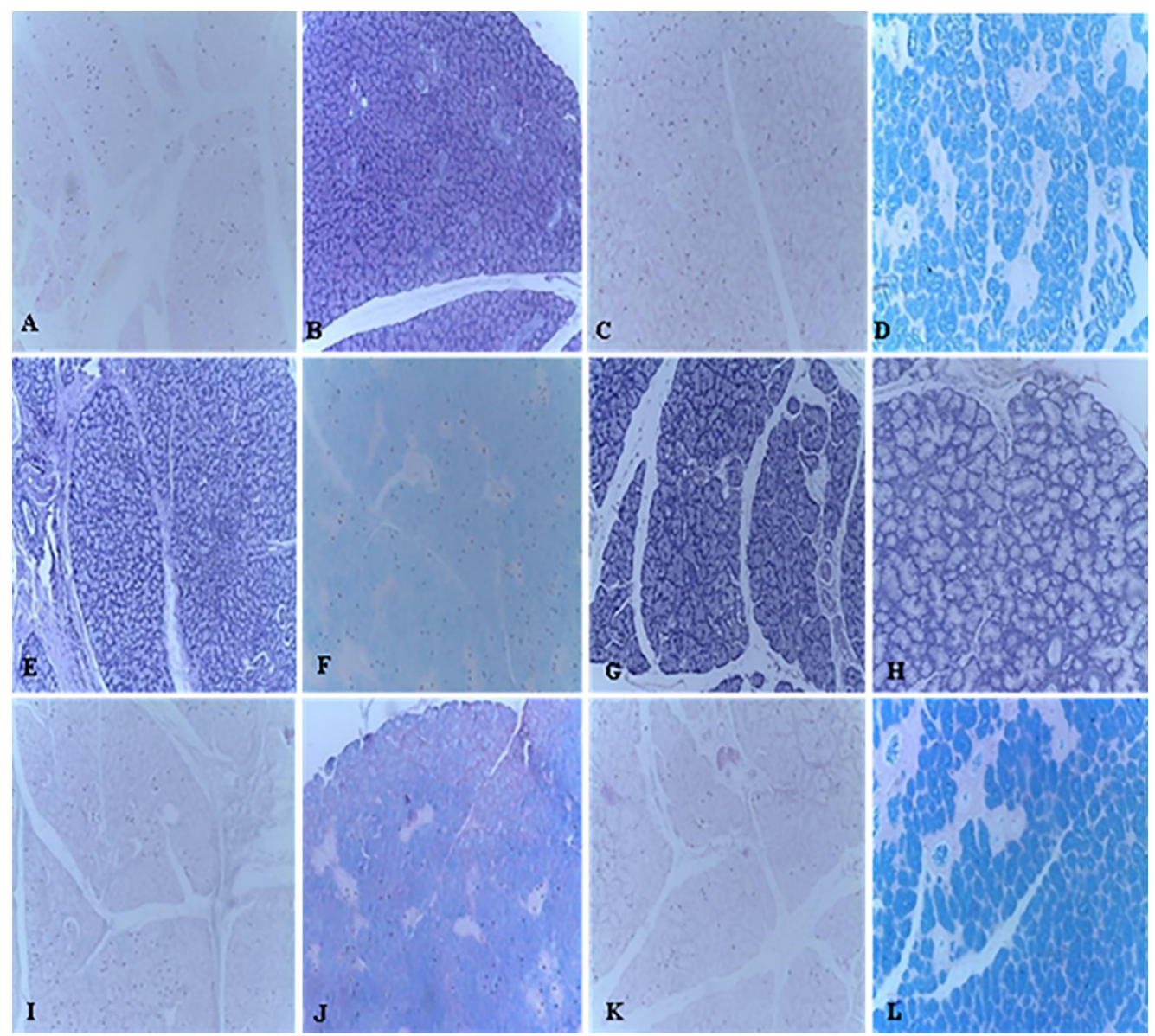

Fig.5. Análise histoquímica das glândulas salivares de cuitas. (A) Os ácinos não se coraram pelo Alcian Blue (2,5). (E) A parótida corou-se pouco pelo método PAS. (I) A parótida não se corou na associação PAS e AB. (B) No método Alcian Blue (2,5) os ácinos da mandibular pouco se coraram. (F) No método PAS, a mandibular se corou um pouco mais intensamente que a parótida. Em J, na associação entre PAS e AB, verifica-se uma fraca coloração. (C) A zigomática não se corou pelo método Alcian Blue $(2,5)$. (G) Glândula foi positiva para o método PAS. (K) Não se corou na associação PAS e AB. (D) A sublingual corou-se fortemente para o método Alcian Blue $(2,5)$. (H) Foi pouco positivo para o método PAS. (L) Corou-se fortemente na associação PAS e AB. Obj.10x.

dos ácinos eram basofílicos, pequenos e encontravam-se na região basal da célula. As células serosas eram piramidais, possuíam um citoplasma volumoso e repleto de grânulos de secreção. A região basal das células era basofílica, assim como seus núcleos, que por sua vez estavam dispostos basalmente. Estes eram pequenos e redondos (Fig.4G e 4H).

Histoquimicamente a parótida não se corou pelo Alcian Blue (2,5) (Fig.5A). e nem na associação entre Alcian Blue e Ácido Periódico de Schiff (Fig.5E), indicando que é pobre em carboidratos complexos. No entanto, apresentou uma fraca positividade para o método Ácido Periódico de Schiff (Fig.5I), o que sugere que há uma fraca ação secretora de mucoproteínas. A mandibular corou-se fracamente pelo Alcian Blue (2,5) (Fig.5B) e também pela associação Alcian Blue e Ácido Periódico de Schiff (Fig.5J), indicando que o muco produzido por estes ácinos é pouco ácido. No método PAS, a mandibular corou-se um pouco mais fortemente que a parótida (Fig.5F), indicando uma fraca produção de mucoproteínas, mucopolissacarídeos, monossacarídeos e mucinas. A zigomática, apesar de ser mucosa, corou-se fracamente com o Alcian Blue (Fig.5C) e na associação Alcian Blue e Ácido Periódico de Schiff (Fig.5K), demonstrando que os grânulos mucosos eram constituídos de carboi- dratos pouco ácidos. Pelo método PAS, a glândula mostrou positividade à reação, indicando provável produção de mucoproteínas (Fig.5G). Os ácinos mucosos da sublingual coraram-se fortemente com o Alcian Blue (2,5) (Fig.5D), adquerindo uma coloração azul turquesa, demonstrando que o muco produzido era ácido, mostrou positividade para a coloração PAS (Fig.5H) e corou-se na associação Alcian Blue e PAS (Fig.5L)

Pela microscopia de transmissão, observou-se que os ácinos serosos das glândulas parótidas possuíam grande quantidade de retículo endoplasmático rugoso na região basal, dispostos ao redor do núcleo celular, enquanto na região apical havia abundantes grânulos de secreção, estes grânulos possuíam um ponto eletrodenso em seu interior. A glândula mandibular possuía células mucosas piramidais e grande parte do citoplasma era preenchido por grânulos de secreção, que estavam distribuídos desde a região basal, até a região apical do citoplasma celular. As células acinares da glândula zigomática possuíam forma de cúbica a piramidal baixa, citoplasma tomado por grânulos de secreção e distribuídos por todo o citoplasma.

Na região basal verificou-se o retículo endoplasmático rugoso bastante desenvolvido e muitas mitocôndrias, in- 
dicativo de intensa atividade celular. As células acinares sublinguais, a exemplo do observado nas demais glândulas salivares, mostraram-se delimitados por septos de conjuntivo oriundos da cápsula presente nesta glândula. Suas células secretoras variaram de cúbicas a piramidais baixas e continham grânulos mucosos distribuídos apicalmente. Os núcleos dispunham-se na região basal do citoplasma celular, eram redondos e eletrodensos. Verificou-se que os ductos intercalares eram constituídos por epitélio cúbico simples. 0 citoplasma destas células possuía poucas mitocôndrias dispersas e os núcleos eram grandes, pouco eletrodensos e com nucléolo organizado (Fig.6A e 6B). Os ductos granulosos eram de fato caracterizados pela presença de células cúbicas a colunares baixas, e possuíam grânulos de secreção na região apical. 0 núcleo era pouco eletrodenso e os nucléolos pouco organizados, indicando
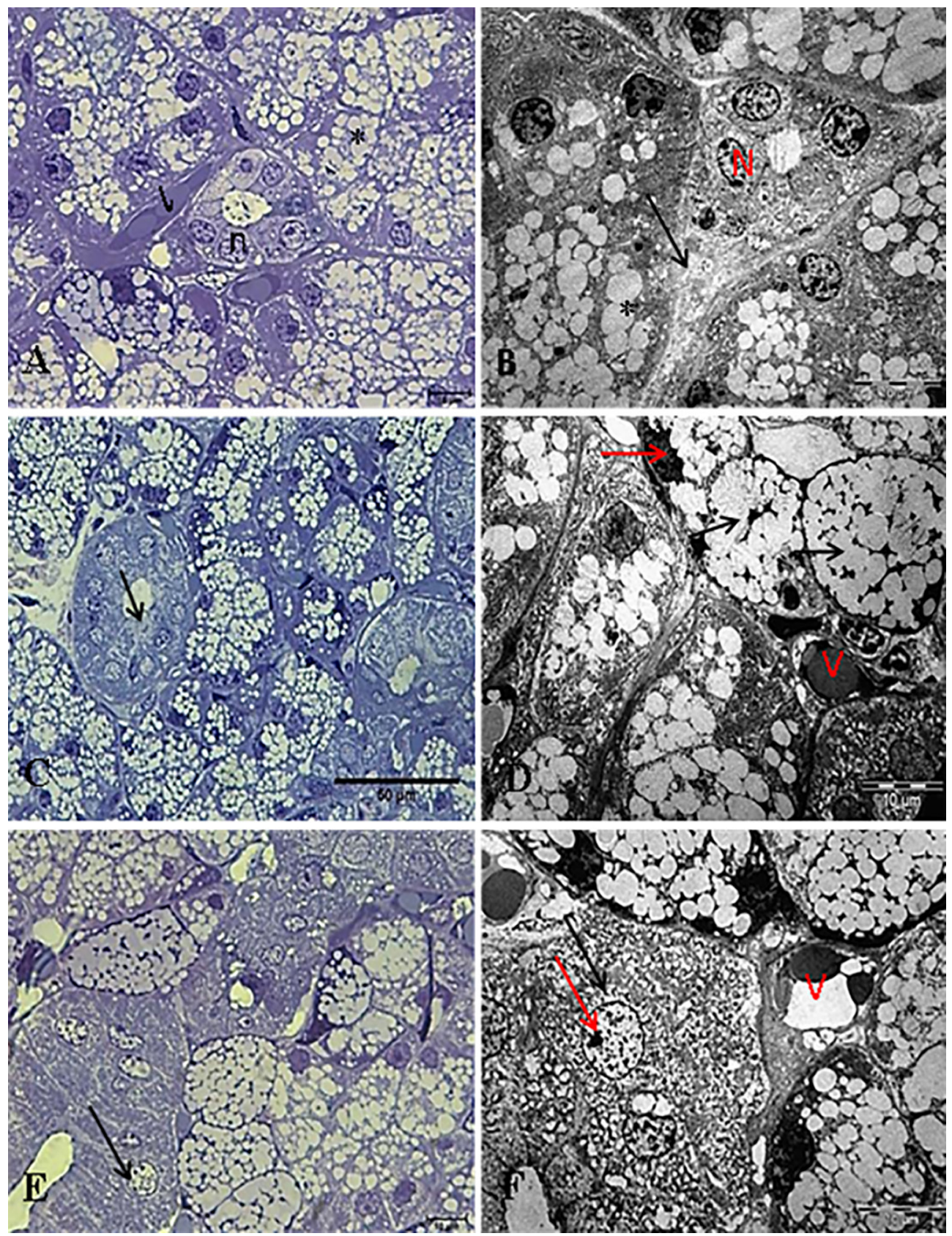

Fig.6. Eletromicrografias dos ductos das glândulas salivares de cutias. (A) 0 ducto intercalar de cutia era constituído por células cúbicas, com núcleos (n) grandes e esféricos, estas células se uniam e formavam o lúmen do ducto (L), próximo ao ducto, há a presença de vasos sanguíneos (V). As células acinares circundantes estão repletas de grânulos de secreção (asterisco). (B) 0 ducto intercalar é rodeado por tecido conjuntivo (seta preta), suas células são colunares e seu núcleo é grande e esférico. Os nucléolos estão organizados. As células acinares adjacentes estão repletas de grânulos de secreção (asterisco). (C) Ducto granular da glândula mandibular de cutia. Observam-se grânulos na sua porção apical (setas vermelhas). Os núcleos celulares estavam próximo à base celular. (D) Células ductais contendo vários grânulos de secreção (setas pretas). 0 núcleo é pouco eletrodenso e o nucléolo (seta vermelha) bem organizado. (E) 0 ducto estriado possuía células colunares e núcleos (seta preta) alongados e centralmente localizados. (F) Ducto estriado continha núcleos (seta preta) pouco eletrodensos e um nucléolo (seta vermelha) bem organizado. (A,C,E) Coloração Azul de Toluidina. 

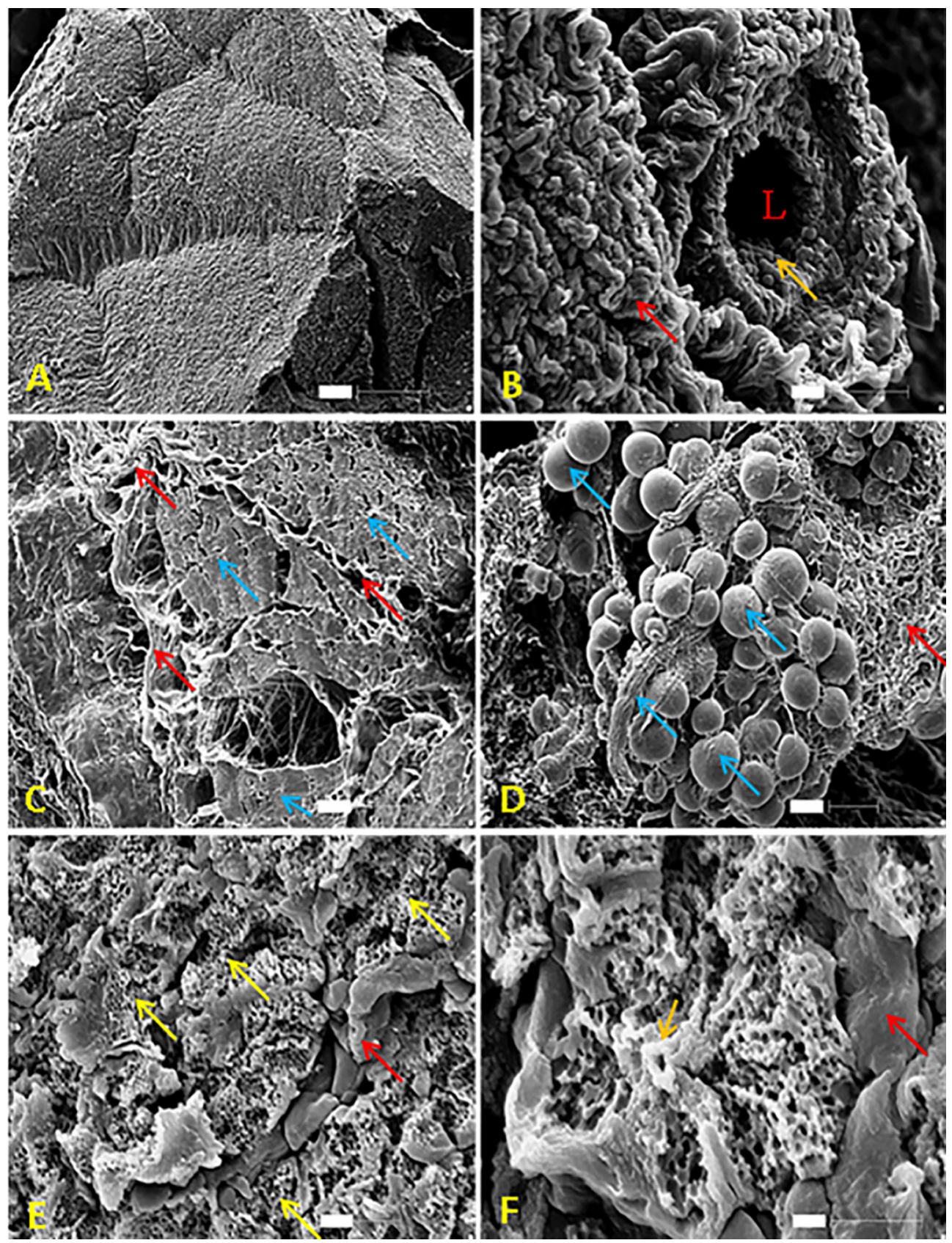

Fig.7. Eletromicrografias das glândulas salivares de cutia. (A) Cápsula de tecido conjuntivo da glândula mandibular. (B) Ducto da glândula zigomática rodeado de tecido conjuntivo (setas vermelhas), no centro do ducto encontra-se o lúmen (L) ductal, verifica-se também grânulos de secreção (setas laranjas) no centro do ducto. (C) Lóbulos (setas azuis) da glândula parótida delimitados por septos de tecido conjuntivo (setas vermelhas). (D) A disposição dos ácinos (setas azuis) da glândula parótida, lembrando um cacho de uva. (E) Vários ácinos (setas amarelas) da glândula mandibular. (F) Porção apical de um ácino (seta laranja) da glândula zigomática ao redor do ácino, tem-se fibra colágena (seta vermelha).

a presença de atividades celular (Fig.6C e 6D). Já os ductos estriados eram constituídos por células colunares simples, com citoplasma com muitas mitocôndrias dispersas, no ápice das células observou-se a presença de junções GAP. 0 núcleo era grande, pouco eletrodenso e localizava-se na região central da célula (Fig.6E e 6F).

Na microscopia de varredura as glândulas salivares estavam revestidas por uma cápsula de tecido conjuntivo e este tecido invadia o parênquima dividindo a glândula em lóbulos chegando a definir os limites ductais e acinares. As células acinares uniam-se e formavam o lúmen do ácino, estes ácinos estavam dispostos de uma forma que lembrava cachos de uvas. Esta técnica também permitiu que se pudesse afirmar que os ductos possuíam aspecto enovelado (Fig.7).

\section{DISCUSSÃO}

Para Treuting \& Dintzis (2012) em camundongo citam que a mandibular é a maior das glândulas salivares, lobulada e localizada ventralmente na média linha do pescoço, rela- 
cionando-se com os linfonodos mandibulares. A descrição feita para camundongos está para aquela observada em cutias, tanto no que se refere a topografia como ao que se refere à lobação, estando inclusive parcialmente encoberta pela parótida, a exemplo do que é descrito para alguns carnívoros como o quati e o mão-pelada (Santos et al. 2010, 2012, Santos 2013). Ressalta-se ainda a relação da glândula com o músculo digástrico, da mesma forma que observado em humanos (Treuting \& Dintzis 2012). A glândula parótida da cutia era a maior entre as quatro glândulas salivares maiores identificadas e localizava-se na base da orelha, sendo semelhante ao verificado em Gracilinanus microtarsus (Lobo, 2014). Os resultados definidos para cutias, no que concerne a glândula zigomática, permite inferir que a localização topográfica é correspondente àquela observada em veados por Frey et al. (2001) e ainda a aquela descrita por Vieira (2015) em cuíca e a descrição feita por Mohammadpour (2009) ao estudar gatos da raça shorthair.

Amano et. al. (2012), estudando a glândula sublingual de ratos e demais glândulas salivares maiores, descreve sua topografia e afirma que esta encontra-se rostralmente associada aos glânglios linfáticos mandibulares, glândulas com as quais também fazem sintopia. Contudo, não inferem em seus resultados se esta possuem lobação. Em cutias, verificou-se que a glândula sublingual era envolta por uma cápsula discreta e constituída por vários lobos. Além disso, localizava-se próximo ao ângulo da mandíbula e apresentava uma porção polistomática e outra monostomática. Em camundongos (Treuting \& Dintzis 2012), consideram que esta localiza-se anteriormente à glândula mandibular e é constituída de um único lobo. Esta estes achados diferem dos encontrado para cutias, onde a mesma é multilobada e situa-se abaixo da mandibular.

Os ductos salivares encontrados nas cutias assemelham-se aos descritos por Santos (2013) no mão-pelada, nessa espécie os ductos intercalares estão bem próximos aos ácinos e ramificam-se em ductos maiores e mais complexos. A histologia dos ductos intercalares, estriados e excretores de cutias, está em conformidade ao encontrado por Ikpegbu et al. (2013) estudando o rato gigante africano e também ao encontrado no mão-pelada (Santos 2013).

Nas glândulas parótidas de cutias, verificou-se exclusivamente a presença de ácinos serosos, semelhante ao que relatam Khojasteh \& Delashoub (2012) ao descreverem a parótida de hamster e aos resultados citados por Vieira (2015)) em estudos comas glândulas salivares da cuíca . Em cutias, estes ácinos estão muito próximos, acham-se separados por uma fina fita de tecido conjuntivo e constituem-se de células cúbicas a piramidais, similarmente ao que afirmam Khojasteh \& Delashoub (2012) para hamster, que observaram células acinares que variaram do cúbico ao piramidal, com núcleos esféricos e localizados basalmente. Salienta-se ainda, a presença de células mioepiteliais identificadas na parótida de cutias, igualmente ao descrito por este último autor em pesquisa com hamster.

Assim, com base nos resultados obtidos da análise da glândula mandibular de cutias, verifica-se que a espécie possui o mesmo padrão constitucional dos roedores citados e mesmo de carnívoros como o quati e ainda ao refe- renciado na literatura para carnívoros como o quati (Santos et al. 2010).

A glândula zigomática de cutias era encoberta por uma cápsula conjuntiva, continha lóbulos e compunha-se de porções acinares e mucosas, o que permite que é a exemplo das sublinguais e mandibulares, se afirme que a mesma é do tipo mista, prevalecendo a porção mucosa. Desta forma os resultados descritos para o roedor em questão, coincide com os relatados para os animais pesquisados por Frey et al. (2001) e Mohammadpour (2009). Contudo, difere do que infere Frey et al. (2001), quanto ao fato de prevalecer no cervídeo estudado, células acinares serosas, já que na espécie objeto deste estudo observou-se que predominam as células acinares do tipo mucosas. Histoquimicamente, a zigomática de cutias diferiu do observado em hamster por Kronman et al. (1968), pois em cutias essa glândula pouco se corou pelo Alcian Blue, dessa forma, assemelhando-se aos resultados de Al-Gailani et al. (1981).

Em cutias as glândulas salivares possuíam tanto ácinos com função exclusivamente serosa ou mucosa, como também ácinos seromucosos, o que as diferenciam do padrão usualmente descrito para humanos (Troxler et al. 1997). Nestes animais constatou-se ainda que a maioria dos ácinos eram de natureza mucosa e coravam-se pelo métodod PAS, assim como em camundongos ratos selvagens e domésticos (Siuda \& Szymanska 1961). Além disto, suas células possuíam forma piramidal, citoplasma abundante e repleto de grânulos de secreção. Estes resultados permitem que se possa afirmar que as glândulas salivares de cutias possuem o mesmo padrão microscópico descrito por Amano et al. (2012) estudando as glândula salivares de humanos e ratos, e ainda ao que afirma Treuting \& Dintzis (2012), quando se refere à forma das células acinares das glândulas sublinguais de camundongos.

Em cutias, verificou-se a presença de ductos intercalares e estriados, estes ductos possuíam células unidas de modo a formar um lúmenJacob \& Poddar (1987) inferiram que esta era composta por ácinos contendo cerca de 4 a 5 células piramidais. Estas células eram dotadas de inúmeras microvilosidades projetadas para o lúmen ácinar. Além disto, continham complexos de Golgi abundante e retículo endoplasmático rugoso e ribossomos livres escassos. Os grânulos de secreção eram circulares, eletrodensos, de tamanhos diferentes e apresentavam um ponto mais denso no centro. Os núcleos das células acinares localizavam-se na sua zona basal. Células mioepiteliais podiam ser vistas aderidas aos ácinos por meio de desmossomos.

Em cutias as células acinares serosas da glândula parótida apresentaram-se com forma piramidal e em seu interior foram observados inúmeros grânulos de secreção com baixa eletrodensidade e apresentavam um ponto altamente denso em seu interior, a exemplo do que verificaram Jacob \& Poddar (1987) em estudos com furões. Quanto à forma dos ácinos seromucosos, estes tinham forma de semiluas serosas, em todas as glândulas salivares estudadas, diferentemente do que verificou Yamashina et al. (1999) em estudos com glândulas salivares sublinguais. Nas células serosas e mucosas componentes dos ácinos glandulares, o citoplasma era volumoso e o complexo de Golgi, retículo 
endoplasmático rugoso e as mitocôndrias eram abundantes, indicando intensa atividade celular. Já os núcleos celulares situavam-se sempre em posição basal, diferindo do que verificou Xin et al. (2005) estudando glândulas mandibular de mini porcos, pois observaram que nestes os núcleos situavam-se em um dos lados da célula ácinar.

Os achados na microscopia eletrônica de varredura permitiram identificar o aspecto lobulado das glândulas, a presença de tecido conjuntivo delimitando os lóbulos e ductos. Além de permitir observar a presença de grânulos de secreção no interior dos ductos e dos ácinos propriamente ditos. Observações semelhantes têm sido realizadas por Watanabe et al. (1996), D’Avola et al. (2006) e Pícoli et al. (2011).

\section{REFERÊNCIAS}

Al-Gailani M., Asking B., Emmelin N. \& Garrett J.R. 1981. Functional and structural studies concerning the control of activity in zygomatic glands of cats. J. Auton. Nerv. System 3:71-86.

Amano O., Mizobe K., Bando Y. \& Sakiyama K. 2012. Anatomy and histology of rodent and human major salivary glands. Acta Histochem. Cytochem. 45(5):241-250.

Carleton M.D., Musser G.G. 2005. Order Rodentia, p.745-752. In: Wilson D.E. \& Reeder D.M. Eds), Mammal Species of the World: a taxonomic and geographic reference. Vol.2. 3rd ed. Johns Hopkins University Press, Baltimore.

D’Avola T.E., Ogawa K., Alves e Silva M.R.M., Motoyama A.A., Inácio E., König Junior B. \& Watanabe I.S. 2006. Three-dimensional characteristics of submandibular salivary gland of ageing rats: an HRSEM study. Annals Anat. 188:431-438.

Deutsch L.A. \& Puglia L.R.R. 1988. Os Animais Silvestres. Globo, Rio de Janeiro, p.51-60.

Emmons L. \& Feer F. 1997. Neotropical Rainforest Mammals: a field guide. 2nd ed. University of Chicago, Chicago.

Frey R., Markgraf U. \& Hofmann R.R. 2001. Evolutionary morphology of the zygomatic gland and lacrimal bulla in roe deer Capreolus capreolus Linnaeus, 1758 (Mammalia, Cervidae). Zoologischer Anzeiger 240:181195.

Ikpegbu E., Nlebedum U.C., Nnadozie O. \& Agbakwuru I.O. 2013. The submandibular salivary gland microscopic morphology of the adult African giant pouched rat (Cricetomys gambianus Waterhouse, 1840). Iranian J. Vet. Med. 7(2):117-122.

Jacob S. \& Poddar S. 1987. Ultrastructure of the ferret parotid gland. J. Anat. 152:37-45.

Khojasteh S.M.B. \& Delashoub M. 2012. Microscopic anatomy of the parotid and submandibular salivary glands in European hamster (Cricetus cricetus L.). Int. Res. J. Appl. Basic Sci. 3(7):1544-1548.

Kronman J.H., O’Donnell L.J. \& Chauncey H.H. 1968. Morphologic and histochemical comparison of the zygomatic, lacrimal, and sublingual glands in the female golden hamster. J. Dental Res. 47(2):207-213.
Lobo L.M., Dos Sanos A.C., Rosa R.A., Ambrósio C.E., Briane D.C., Costa G.M., De Carvalho A.F. \& Mançanares C.A.F. 2014. Estudo macroscópico do aparelho digestório de Gracilinanus microtarsus (Wagner, 1842) (Mammalia: Didelphidae). Biotemas 27:109-120.

Marcelo J.P.P. 2005. Projeto Cutia (Dasyprocta sp.). Disponível em <http://72.14.207.104/search?q=cache:gLtrS2 Nm5 MIJ:esam.br/ cppgcemasprojetoscutia.asp+esam.br/cppgcemasprojetoscutia\&hl=pt-BR\&lr=lang_pt> Acesso em 3 nov. 2011.

Mohammadpour A.A. 2009. Investigations on the shape and size of molar and zygomatic salivary glands in shorthair domestic cats. Bulgarian J. Vet. Med. 12(4):221-225.

Nowak R.M. \& Paradiso J.L. 1991. Order Rodentia, p.561. In: Walker's Mammals of the World. 5th ed. The Johns Hopkins University Press, Baltimore.

Pícoli L.C., Dias F.J., Issa J.P.M., Ogawa K., Ciena A., Iyomasa M.M., Lopes R.A. \& Watanabe I. 2011. Ultrastructure of submandibular salivary glands of mouse: TEM and HRSEM observations. Microsc. Res. Tech. 74:11541160.

Santos A.C., Bertassoli B.M., Oliveira V.C., Rosa R.A., Carvalho A.F. \& Mançanares C.A.F. 2010. Caracterização morfológica das glândulas salivares mandibulares dos quatis (Nasua nasua Linnaeus, 1758). Revta FZVA, Uruguaiana, 17(2):276-286.

Santos A.C., Bertassoli B.M., Oliveira F.D., Oliveira D.M., Oliveira V.C., Vasconcelos B.G., Carvalho A.F., Mançanares C.A.F. \& Assis Neto A.C. 2012. Estrutura macro e microscópica das glândulas salivares parótidas em duas espécies de procionídeos: mão-pelada (Procyon cancrivorus G. Cuvier, 1798) e quati (Nasua nasua Linnaeus, 1766). Biotemas 25(1):93101.

Santos A.C., Oliveira V.C., Viana D.C., Lobo L.M., Ambrósio C.E., Assis-Neto A.C., Carvalho A.F. \& Mançanares C.A.F. 2013. Análise microscópica e ultraestrutural das glândulas salivares mandibulares de Procyon cancrivorus. Pesq. Vet. Bras. 33(Supl.1):39-44.

Siuda S. \& Szymanska Z. 1961. Comparative investigations of the salivary glands of small rodents. Acta Theriologica 5:141-154.

Troxler R.F., Iontcheva I., Oppenheim F.G., Nunes D.P. \& Offner G.D. 1997. Molecular characterization of a major high molecular weight mucin from human sublingual gland. Glycobiology 7(7):965-973.

Treuting P.M. \& Dintzis S.M. 2012. Salivary glands, p.111-119. In: Treuting P.M., Dintzis S.M., Frevert C.W. \& Liggitt D. (Eds), Comparative Anatomy and Histology: a mouse and human atlas. Elsevier, Seattle.

Vieira B.S., Schuingues C.O., Lima M.G., Martins Daniele S. \& Costa Gerlane M. 2015. Morfologia das glândulas salivares de Glironia venusta Thomas, 1912 (Didelphimorphia). Pesq. Vet. Bras. 35(2):199-207.

Watanabe L.I., Seguchi H., Okada T., Kobayashi T., Jin Q.S. \& Jiang X.D. 1996. Fine structure of the acinar and duct cell components in the parotid and submandibular salivary glands of the rat: a TEM, SEM, and HRSEM study. Histol. Histopathol. 11:103-110.

Xin Z., Jun L., Xiao-Yong L., Yi-Lin S., Chun-Mei Z. \& Song-Ling W. 2005. Morphological characteristics of submandibular glands of miniature pig. Chin. Med. J. 118(16):1368-1373.

Yamashina S., Tamaki H. \& Katsumata O. 1999. The serous demilune of rat sublingual gland is an artificial structure produced by conventional fixation. Archs Histol. Cytol. 62(4):347-354. 